\title{
BATAILLE EN EL ANTI EDIPO
}

\author{
Vicente Montenegro Bralic*
}

\begin{abstract}
Resumen / Abstract
Se analiza la importancia de Bataille en El Anti Edipo (AE) de Deleuze y Guattari (D-G), para mostrar la deuda o filiación entre la noción de "gasto improductivo" y la noción de "producción deseante". Explicando el sentido de la primera en el marco de una economía general, se muestran afinidades entre dicha reflexión y la propuesta de D-G en $A E$, en relación con una lectura de la tesis marxiana sobre la identidad entre hombre y naturaleza. Se concluye con posibles inscripciones que los trabajos de Bataille y de D-G pueden tener en la trayectoria del marxismo y del pensamiento contemporáneo.

Palabras clave: gasto improductivo, economía general, El Anti Edipo, producción deseante, materialismo.

\section{BATAILLE IN ANTI-OEDIPUS}

The article stresses the relevance of Bataille in Deleuze and Guattari's (D-G) AntiOedipus(AE), to show the debt or affiliation between the notion of "improductive expenditure" and that of "desiring production". Framming the sense of the former in a general economy, afinities between such thinking and the project of D-G in AE are shown, having in sight a certain reading of the marxian thesis of the identity between man and nature. Conclussions are drawn upon possibles reinscriptions that Bataille and $D-G$ 's works may have in the history of marxism and contemporary thought.
\end{abstract}

KEYWORDS: improductive expenditure, general economy, Anti-Oedipus, desiring production, materialism.

39 Rue Lejeune, 31000, Toulouse, Francia. v.montenegrobralic@gmail.com. Estudiante de Doctorado en Filosofía, Université de Toulouse II-Jean Jaurès y Università degli Studi di Milano-Bicocca. Becario del Programa de Becas Chile para Doctorado en el extranjero (CONICYT, Gobierno de Chile). 
Los dos movimientos principales son el movimiento rotativo y el movimiento sexual, cuya combinación se expresa mediante una locomotora compuesta de ruedas y de pistones.

Estos dos movimientos se transforman uno en otro reciprocamente.

De este modo constatamos que la tierra al girar hace copular a los animales y a los hombres, y (como lo que resulta es también la causa de lo que provoca) que los animales y los hombres hacen girar a la tierra copulando.

Georges Bataille (1927)

\section{Introducción}

RA El término "producción deseante"es tal vez una de las nociones más importantes que organizan la apuesta filosófica de El Anti Edipo $(A E)$ de Deleuze y Guattari (D-G), y quizás uno de los conceptos más innovadores y que mayor atención ha despertado entre sus comentaristas ${ }^{1}$. De manera general, se trata de un concepto que discute frontalmente la noción psicoanalítica del deseo como falta -especialmente en Freud, pero también en Lacan (o en cierta lectura que el propio texto lacaniano pareciera autorizar)-, y en cambio, propone comprenderlo como un proceso material de flujos de materia y energía (tanto geológica o bioquímica, como orgánica y social).

Aunque la elaboración de tal concepto es producto de una compleja constelación que incorpora nociones propias del psicoanálisis, la filosofía de Marx y la filosofía de Nietzsche $^{2}$, en las primeras páginas de $A E, \mathrm{D}-\mathrm{G}$ mencionan dos importantes trabajos de Georges Bataille, como referencias que inspiran su concepción: La noción de gasto $(N G)$ y La parte maldita $(P M)$. Aunque el nombre de Bataille es mencionado solo dos veces a lo largo de $A E$, la referencia inicial a sus obras y el significado que otorgan D-G a la noción de producción deseante, permiten atribuir al primero un lugar bastante más decisivo en la propuesta teórica general que ofrece $A E$ que una simple referencia bibliográfica adicional entre las abundantes fuentes teóricas que la alimentan.

Lo que se propone en este trabajo es perfilar y destacar el lugar que ocupa Bataille -y su noción de "gasto improductivo" [dépense improductive]-en la reflexión

$1 \quad$ Ver Sibertin-Blanc (2010); Holland (1999); Buchannan (2008); Mengue (2008, pp. 269298); Zourabichvili (2003).

2 Es claro que en dicha síntesis habría que incluir también -y al menos- a Spinoza. Como sostuvo Deleuze en Pourparlers, "El Anti-Edipo planteaba la univocidad de lo real, era una especie de spinozismo del inconsciente" (Deleuze 1996, p. 230). Si aquí lo dejamos de lado, es debido a la relación y la problemática específica que aquí nos interesa abordar. Holland establece como marco interpretativo general los "tres grandes materialismos" que representarían Marx, Nietzsche y Freud, pero añade en nota al pie que allí habría que añadir también a Bataille, Bergson y Spinoza (Holland 1999, p. 4 y nota 10 en p. 125). 
que motiva la elaboración teórica de $A E$, particularmente desde su concepción de un materialismo como "proceso de producción" que considera el gasto como formando parte de un flujo de materia y de energía, o bien, siguiendo el lenguaje empleado por Deleuze en su lectura de Nietzsche, como formando parte de un "campo de fuerzas" antagónicas en constante devenir" ${ }^{3}$. De esta manera, el propósito de este trabajo es doble: interesa poner de relieve no solo el grado en que el concepto de producción deseante de D-G estaría en deuda con la noción de gasto propuesta por Bataille, sino también, en qué medida la apropiación de tal noción se halla estrechamente vinculada a una determinada comprensión del materialismo (por no decir, de cierta "ontología materialista" que podría estar en juego en $A E$ ), cuestión que permitiría observar cierto terreno común a Bataille y Deleuze en relación con un materialismo que, de la mano de Nietzsche, se piensa al margen de toda dialéctica (lo que implica, sin duda, una confrontación crítica con el marxismo, en cuanto materialismo histórico).

\section{Lo que puede una nota al pie. El lugar de Bataille en El Anti Edipo}

La referencia a Bataille en $A E$ ocurre, ya lo decíamos, al inicio de dicha obra, apenas transcurridas tres páginas del texto, específicamente en la tercera nota al pie ${ }^{4}$. Siendo el único pasaje donde se citan directamente los trabajos de Bataille, conviene reproducir aquí la nota al pie en su totalidad:

Cuando Georges Bataille habla de gastos o consumos suntuarios, no productivos, en relación con la energía de la naturaleza, se trata de gastos o consumos que no se inscriben en la esfera supuestamente independiente de la producción humana en tanto que determinada por "lo útil": se trata, por tanto, de lo que nosotros llamamos producción de consumo [production de consomation] (Deleuze y Guattari 2009, p. 13n).

La nota aparece cuando D-G se preguntan por lo que significa "proceso", señalando de entrada una de las tesis sobre las que habrá que detenerse una y otra vez, a saber, la identidad entre naturaleza y producción, cuestión que, como queda en evidencia en las siguientes páginas ( $\mathrm{y}$ de nuevo, en la nota al pie inmediatamente a continuación, donde citan un importante trabajo de Gérard Granel $)^{5}$, no es sino la tesis que Marx había ya instalado cuando se refería al "ser genérico" (Gattungswesen) en los Manuscritos de 1844: "la relación del hombre con la naturaleza es inmediatamente su relación con el hombre, del mismo modo que la relación con el hombre es inmediatamente su relación con la naturaleza, su propia determinación natural"' (2009, p. 138).

Ver Deleuze (1986).

Citamos de la edición castellana (Deleuze y Guattari 2009). En el original francés (Deleuze y Guattari 1972), la nota aparece transcurridas cuatro páginas (p. 10).

Se trata de "La ontología marxista de 1844 y la cuestión del 'corte"” (Granel 2014), trabajo que aquí tendremos muy presente y que comentaremos más adelante. 
Partamos por señalar de manera resumida qué es lo que Bataille había intentado pensar bajo la noción de gasto improductivo, y en qué sentido ello era entendido como formando parte de un movimiento general de la energía de la naturaleza. En el temprano ensayo de 1933, Bataille pretendía dar cuenta de un "principio de pérdida" inevitable e irreductible que regía las actividades humanas, y que ponía seriamente en cuestión el principio de utilidad clásico de la economía política. Aunque este principio de pérdida ha sido siempre considerado extraño a la producción y al intercambio económico (al punto que "el odio al gasto es la razón de ser y la justificación de la burguesía", aunque al mismo tiempo, "el principio de tu terrible hipocresía" [Bataille 2003, p. 126]), Bataille pretende mostrar la imposibilidad de reducir o excluir este principio, pues resulta indisociable de la esfera de la producción (de allí que aparezca como una "parte maldita"). Ocurre así que mientras el foco de atención esté puesto en los procesos de producción o adquisición como los dos aspectos fundamentales de la actividad humana, se permanece en una "estrechez de juicio" que impide reconocer la cuestión decisiva: la función social del gasto improductivo. Bataille distingue dos modalidades de "consumo": una primera forma está subordinada a la conservación de la vida y a la prolongación del proceso productivo; en cuanto consumo instrumental es, por tanto, una forma de consumo útil. Pero una segunda forma de consumo puede reconocerse en aquellos gastos que no tienen otra finalidad que la pura pérdida que ellos mismos constituyen, es decir, son formas de gasto improductivo, y cuyos ejemplos Bataille identifica con el juego, el arte, la sexualidad, el sacrificio, entre otros motivos. En este segundo caso, se trata de actividades que tienen su fin en sí mismas, y por ello se las puede considerar actividades no subordinadas o también "soberanas". Ellas ponen en evidencia un principio de pérdida, contrario al principio económico de la adquisición (ya sea para mantener el equilibrio en la conservación, o bien, para el crecimiento en la acumulación), y es en definitiva a esta segunda forma de consumo a la cual debemos reservar propiamente el nombre de gasto, "excluyendo todos los modos de consumo que sirven de término medio para la producción" (Bataille 2003, p. 114). Lo que en $N G$ Bataille pretendía demostrar, era que toda operación económica contemplaba necesariamente dos lados: uno productivo y otro improductivo. De modo tal que el gasto improductivo, como dicen D-G, no se inscribe en ninguna esfera independiente de la producción humana en tanto que dominada por lo útil, sino que forma parte de un mismo y único proceso.

$6 \quad$ Sobre el concepto de soberanía, ver Bataille (1996). En una reconstrucción genealógica del concepto de energía en Bataille, Wendling establece al menos tres de sus fuentes: la biología evolutiva, el estructuralismo y la doctrina medieval de la "emanación". Sin ser incorrecto, pareciera que otras fuentes también son posibles en tal genealogía, como lo demuestra su mención a Nietzsche, por ejemplo, al hablar precisamente del "individuo soberano" como una versión del noble nietzscheano: "Como Nietzsche, Bataille sostiene que las sociedades burguesas... han hecho este tipo de consumo imposible para nosotros, al invertir los valores asociados a él” (Wendling 2007, pp. 37, 47). 
En este ensayo, Bataille intenta esbozar una concepción radicalmente distinta del proceso de la economía, una manera completamente distinta de comprender la producción de las condiciones materiales de la vida, en la cual, se demuestra "el carácter secundario de la producción y adquisición con relación al gasto" (Bataille 2003 , p. 118). Tal comprensión del proceso económico, que más tarde, en $P M$, será desarrollado en la forma de leyes de una economía general (Bataille 2007), sin duda opera cierto quiebre con la crítica de la economía política marxiana, análoga a la que llevan a cabo D-G al introducir el deseo en la infraestructura económica ${ }^{7}$. No tanto en el sentido de que la producción sea secundaria en relación con el gasto, sino, como bien dicen, en el sentido de que

todo es producción: producciones de producciones, de acciones y de pasiones; producciones de registros, de distribuciones y anotaciones; producciones de consumos, de voluptuosidades, de angustias y de dolores. De tal modo todo es producción que los registros son inmediatamente consumidos, consumados, y los consumos directamente reproducidos. Este es el primer sentido de proceso: llevar el registro y el consumo a la producción misma, convertirlos en las producciones de un mismo proceso (Deleuze y Guattari 2009, pp. 13-14).

En esto consiste la "univocidad" del concepto de producción como proceso, y es lo que exige comprender la inmanencia del deseo tanto en las formaciones libidinales como en las formaciones sociales (Sibertin-Blanc 2010). Cuando Bataille declara el carácter secundario de la producción con relación al gasto, no estaría pensando algo muy distinto de lo que D-G definen aquí como "producciones de consumo", pues lo que en $N G$ se piensa en términos de gasto improductivo, evidentemente debe tener también su propia“positividad"; la pura pérdida de la que habla no es estéril, no es pérdida nihilista, sino que ella también produce, tiene efectos sobre lo real que, sin embargo, no son susceptibles de una apropiación utilitaria ${ }^{8}$. El desplazamiento que Bataille intenta

7 Hay que advertir que este modo de expresar lo que D-G realizarían en $A E$ es en rigor inexacto, pues como bien aclara Sibertin-Blanc, "una teoría del modo de producción deseante... debe permitir que se instruya la investidura inmediata del deseo en la infraestructura, en las fuerzas, medios y relaciones sociales de producción. No se trata de ampliar las coordenadas ideológicas de la superestructura integrándole las aventuras de la líbido, sino complejizar la noción de infraestructura rompiendo con un racionalismo objetivista de la producción económica" (Sibertin-Blanc 2010, p. 31). En último término, nos parece que la propuesta de D-G en $A E$-lo mismo que la de Bataille en $P M$ - apuntaría justamente a "deconstruir" esa dicotomía entre infra y superestructura, tornando imposible operar con esa distinción tal y como aparece en algunos textos de Marx (de manera emblemática, desde luego, en el "Prólogo" a la Contribución a la crítica de la economía política de 1859 [Marx 1989]). Sobre este punto, Mengue es más tajante al sostener que en $A E$ "los conceptos marxistas de infra y de súper-estructura, así como el de ideología son, por tanto, anulados” (2008,p. 271).

8 Decir que el "gasto improductivo" también "produce" no constituye una contradicción, pues en un caso "improductivo" se define en contraposición a la productividad utilitaria 
realizar desde una economía restingida a una economía general, busca precisamente demostrar "la constitución de una propiedad positiva de la pérdida" (Bataille 2003, p. 121), cuestión que D-G se esforzarán por demostrar también en relación con el deseo: este no sería expresión idealista, no es representación fantasmática, sino flujo material que produce ${ }^{9}$.

La completa inversión del pensamiento y la moral que exige la perspectiva de una economía general (Bataille 2009) -motivo inequívocamente nietzscheano-, parte pues de la premisa según la cual no es la necesidad, sino su contrario, el lujo o la sobreabundancia, lo que plantea a la materia viva y al hombre sus problemas fundamentales. Similar inversión, podría decirse, es la que opera en el prefijo que se antepone a Edipo: no es el deseo como falta, no es la carencia la que describe los verdaderos problemas psicológicos y sociales, sino al contrario, es el carácter productivo del deseo lo que el esquizoanálisis propuesto por D-G debe atender. En ese sentido, el "Anti-" de $A E$ no tiene el carácter de una antítesis dialéctica que permitiera resolver una contradicción en una más elevada y omnicomprensiva síntesis, sino más bien, apunta a la "des-edipización" - o sea, a la "materialización"- del psicoanálisis y su consiguiente comprensión del deseo. Pues la carencia nunca es primera, dicen, sino que es "el arte de una clase dominante, práctica del vacío como economía de mercado: organizar la escasez, la carencia, en la abundancia de la producción" (Deleuze y Guattari 2009, p. 35). Se trata, como dice Bataille, del "odio al gasto" que constituye la "razón de ser" de la burguesía, pero que refleja a la vez su "terrible hipocresía", pues desconoce la inevitabilidad del gasto improductivo y reniega de todo lo que sea exceso, ocio, goce, aquello que interrumpa u obstaculice la lógica utilitaria de la economía restringida (Bataille 2003, p. 126), aun cuando tales manifestaciones finalmente no hacen más que poner en evidencia los efectos de la "producción como proceso", es decir, los efectos de una "economía general". De la escasez al exceso, de la necesidad a la exuberancia, de la falta a la producción deseante, de la economía restringida a la economía general, se observa así un desplazamiento cuya afinidad se explica por el interés de pensar esa identidad entre naturaleza y producción que la reflexión tanto de Bataille como de D-G estarían poniendo en juego.

Tal identidad resulta mucho más claramente elaborada en $P M$ (de 1949). La economía general allí propuesta por Bataille comprende toda la actividad humana como formando parte del movimiento de la energía del universo. Las leyes de esta economía

del capital (la producción según una economía restringida), mientras que en el otro, la "producción" del gasto refiere a la producción de procesos o acontecimientos que exceden y en último término interrumpen la homogeneidad de la producción utilitarista (es decir, la producción según una economía general). Al respecto, Bataille (2005).

$9 \quad$ Se trata de la particular "crítica de la representación" que D-G elaboran en $A E$ al desplazar la noción de deseo como "falta" e insertarla como parte de un proceso productivo material: con Edipo, "El inconsciente deja de ser lo que es, una fábrica, un taller, para convertirse en un teatro, escena y puesta en escena" (Deleuze y Guattari 2009, p. 61). Ver también Holland (1999, p. 22). 
general, idénticas a las "leyes de la vida", dice Bataille (tenemos aquí la identidad entre producción y naturaleza), parten de la constatación según la cual

el organismo vivo... recibe en principio más energía que la necesaria para el mantenimiento de la vida: la energía (la riqueza) excedente puede ser utilizada para el crecimiento de un sistema (por ejemplo, de un organismo). Si el sistema no puede crecer más, o si el excedente no puede ser enteramente absorbido en su crecimiento, es necesaria la pérdida sin beneficio, el gasto, voluntario o no, glorioso, o al menos, de manera catastrófica (2009, p. 34).

Ahora bien, la totalidad de la riqueza productiva en la superficie del globo se rige por el juego de la materia viva en general, el cual está determinado por un excedente de energía, por una sobreabundancia de energía bioquímica que, en último término, obedece a un segundo hecho elemental: el principio de la exuberancia de la energía solar. Al situar tal principio como fundamento último que constituye las condiciones de posibilidad para la existencia de todo lo vivo y, por ende, de lo humano, la tentativa de Bataille no debe ser entendida como una nueva forma de misticismo o de esoterismo cosmológico -como muy precipitadamente acusó Sartre (1960, pp. 111-145)-, sino al contrario, debe entenderse como un materialismo exacerbado, un exceso de materia o de energía que a la vez referiría a un materialismo excedido. Qué materialismo es el que aquí se excede, evidentemente no es otro que un materialismo idealista o metafísico, incluyendo por cierto el materialismo dialéctico ${ }^{10}$, que será también aquel materialismo con el que D-G discuten y que buscan problematizar. Lo interesante es que, para Bataille, el propio movimiento inmanente de la energía es el que "produce" el gasto o la pérdida, lo queramos o no.

Por su parte, cuando D-G declaran el fin de la distinción hombre-naturaleza, lo hacen teniendo en mente justamente la imposibilidad de distinguir entre la producción económica y la producción de la vida: "La esencia humana de la naturaleza y la esencia natural del hombre se identifican en la naturaleza como producción o industria, es decir, en la vida genérica del hombre. La industria ya no se considera entonces en una relación extrínseca de utilidad, sino en su identidad fundamental con la naturaleza como producción del hombre y por el hombre" (Deleuze y Guattari 2009, p. 14). La producción deseante es así la identidad entre el deseo como esencia natural del hombre, y la producción económica como esencia humana de la naturaleza. Afirmar que ya no es

10 Sollers decía en 1967 que el materialismo de Bataille planteaba el problema de "la otra cara" del materialismo dialéctico (1977, p. 118). Macherey, a su vez, se refiere al materialismo de Bataille como un materialismo no dialéctico, "desdialectizado" o "indialectizable", en un ensayo cuyo título - "Georges Bataille y la inversión materialista" (2003) - insinuaba el paralelismo que se puede establecer entre la "puesta sobre sus pies" de la dialéctica hegeliana realizada por Marx, y la inversión que a su vez hace Bataille, del materialismo de este último. Sobre este tema, remito a otro trabajo en el que abordo más en profundidad esta discusión: Montenegro (2015). Varios de los elementos aquí expuestos han sido inicialmente elaborados allí. 
posible distinguir entre el producir y su producto, es otra manera de plantear esa especie de tautología con que Marx había descrito la actividad del "ser genérico"(Gattungswesen) como la "vida que crea vida" (Marx 2009, p. 112).

Para Bataille, la reflexión en torno al gasto improductivo estaba atravesada por una urgente preocupación política. Junto a $N G$, el año 1933 (año del ascenso de Hitler al poder) Bataille publica La estructura psicológica del fascismo y El problema del Estado. El primero abría con una nota que declaraba explícitamente llevar a cabo una interpretación de la superestructura social del fascismo, dado el rápido descuido por parte del marxismo, de una reflexión detallada en torno a los asuntos que quedaban relegados al campo de la ideología. Allí, distinguía entre la parte homogénea de la sociedad, aquella cuya base era la producción económica, esto es, las actividades útiles, y en la cual la clase burguesa efectúa "la reducción tendencial del carácter humano a una entidad abstracta e intercambiable, reflejo de las cosas homogéneas poseídas" (Bataille 2003, p. 139). Para Bataille, se confirma la tesis marxista según la cual el Estado se concibe al servicio de la homogeneidad amenazada: de allí el potencial fascista y totalitario de toda forma estatal. Sin embargo -y hablando en términos todavía muy cercanos al "materialismo dialéctico"- el proletariado seguiría siendo en gran medida irreductible: al permanecer excluido del beneficio del capital, pasa a formar la parte heterogénea de la sociedad. Mas en general, el mundo heterogéneo lo conforma el conjunto de resultados (o de "productos") del gasto improductivo, y según una lógica de asimilación y excreción, la parte homogénea solo se constituye expulsando y excluyendo los elementos heterogéneos que le resultan inasimilables, aquellos elementos que no le reportan ninguna utilidad (la violencia, el exceso, el deseo, la locura).

Nuevamente es posible descubrir aquí importantes resonancias con el modo en que la "axiomática" capitalista opera desterritorializando y reterritorializando, de acuerdo con lo expuesto por D-G. La complicidad que observan los autores entre la operación edípica del psicoanálisis que remite el deseo a una forma trascendente del inconsciente (un "teatro privado" en vez de un "taller" o una "industria"), y aquel movimiento de desterritorialización del capital que luego se reterritorializa en el trabajo asalariado o en la propiedad privada; lo que hay allí es -para decirlo en términos batailleanosuna exclusión de los efectos del deseo, una exclusión de lo que el deseo produce y que resulta funcional a la producción económica (en realidad, habría que precisar: no tanto mediante su exclusión o su excreción, sino mediante su domesticación, o mejor, mediante su disciplinamiento: "desde que nos introducimos en Edipo, desde que se nos mide con Edipo... se ha suprimido la única relación auténtica: la de la producción" [Deleuze y Guattari 2009, p. 31]).

De cualquier modo, en ambos casos se trata del lugar que le cabe al gasto improductivo, o bien, a la producción deseante. Así como Bataille distingue entre una negación o una afirmación del gasto que daría paso a la homogeneidad fascista o a la heterogeneidad revolucionaria (para Bataille, la revolución incluye al lumpen 
proletariado) ${ }^{11}, \mathrm{D}-\mathrm{G}$ distinguen entre dos formas del deseo: un deseo "paranoico" o "fascista", que pretende reforzar los mecanismos de codificación y territorialización operados por el Estado, y un deseo "esquizofrénico" o "revolucionario", que al contrario, opera "evadiendo códigos" 12 , y desterritorializando las fuerzas o la energía que el capitalismo pretende reterritorializar en la propiedad privada y en la familia.

Me permito aquí una pequeña digresión: en realidad, la primera referencia que D-G hacen a Bataille en $A E$ ocurre de hecho en la primera página, aunque no lo hagan completamente explícito, pues luego de hablar del "enfermo de nervios" de Schreber, escriben, entre dos puntos seguidos: "Ano Solar" (en cursivas). Literalmente, se trata del título de uno de los primeros escritos de Bataille, de 1927, y del cual hemos tomado aquí el epígrafe. Texto bastante obscuro, pero igualmente sugerente para lo que interesa tratar aquí. Cito un pasaje en el que por vez primera se prefigura lo que en varios ensayos posteriores, Bataille llamará "bajo materialismo": "Los obreros comunistas parecen a los burgueses tan feos y tan sucios como las partes sexuales y velludas o partes bajas: tarde o temprano tendrá lugar una erupción escandalosa en el curso de la cual las cabezas asexuadas y nobles de los burgueses serán cortadas" (1997, p. 22).

Lo que Bataille se proponía pensar con la noción de "bajo materialismo" era fundamentalmente un materialismo no dialéctico, esto es, un materialismo que no subordinara la noción de materia a ninguna categoría abstracta, ni tampoco la comprendiera dentro de un orden de cosas jerarquizado (por ejemplo, el de "humanidad/ naturaleza"). En un breve artículo de 1929, titulado precisamente "Materialismo", Bataille decía -cuestión interesante para la relación con $A E$ - que para evitar toda concepción idealista de la materia, "habría que tomar de Freud, entre otros, una representación de la materia, antes que de físicos fallecidos hace tiempo" (2003, p. 29). De nuevo, no tendría sentido un materialismo que conciba el proceso de producción aislado de los procesos de producción deseante, un materialismo que relegue tales procesos psicológicos (el deseo) al plano superestructural de la ideología. De allí que, en otro ensayo de 1930 ("El bajo materialismo y la gnosis") Bataille acudiera al criterio de "lo bajo" o "la bajeza" como el rasgo distintivo de la verdadera materia. La "materia baja" sería todo aquello que es completamente ajeno, extraño, -en una palabra-heterogéneo al idealismo y a la "máquina ontológica", y es justamente la heterogeneidad de esta materia baja lo que le otorga una incongruencia lógica no dialectizable. Así pretendía demostrarlo, cuando en otro ensayo de la época, titulado "El dedo gordo", ofrecía la metáfora del dedo gordo del pie como expresión de ese bajo materialismo, pero también como crítica a todo pensamiento que idealiza la materia. "El hombre, que tiene la cabeza ligera, es decir, elevada hacia el cielo y las cosas del cielo, mira [al dedo gordo] como un escupitajo so pretexto de que pone ese pie en el barro" (Bataille 2003, p. 44). A pesar de que en el

11 Al respecto, ver Grindon (2010).

12 En "Pensamiento nómada", Deleuze señalaba que la ley, el contrato y la institución, eran los grandes instrumentos de codificación. De allí pues que el "pensamiento nómada", como el de Nietzsche, es aquel que libera o hace pasar algo que "no se deja y que jamás se dejará codificar" (2002, p. 352). 
cuerpo humano, dice Bataille, "la sangre fluye en igual cantidad de arriba hacia abajo y de abajo hacia arriba, se ha tomado el partido de lo que se eleva y la vida humana es considerada erróneamente como una elevación" (ibíd.). El hombre desprecia los pies inmersos en el barro, considera repugnante un "órgano" tan bajo como el dedo gordo, y en su lugar, cree que mientras más lejos se encuentre de la inmundicia, su cabeza, erguida en lo más alto del cuerpo, comparte el lugar de los dioses, la pureza de los cielos. Pero como bien recuerda Bataille, en un ensayo que hace explícita su empresa de pensar un materialismo de la mano de Marx y de Nietzsche, "tanto en la historia como en la naturaleza, la podredumbre es el laboratorio de la vida" (1974, p. 284). Se trata de una nota de Marx que al parecer solo ha quedado recogida en la edición francesa de El $_{\text {capital }}{ }^{13}$. Expresa, en todo caso, lo inútil que es pensar la historia como separada de la naturaleza (o lo que es lo mismo, lo humano separado de la animalidad de su deseo), pues la podredumbre de la baja materia, diríamos con Bataille, no es sino la inmanencia de la vida, el flujo inmanente de energía que atraviesa al hombre y la naturaleza ${ }^{14}$.

13 Solo la más reciente edición de El capital publicada por Siglo XXI recoge esta variación en una nota (Marx 2005, p.1071). La edición francesa corresponde a la primera traducción a cargo de Joseph Roy, "una muy pobre traducción, desparejamente revisada por Marx", como advierte Pedro Scaron, a cargo de la traducción castellana (p. VIII). Ella es accesible hoy en la editorial Garnier-Flammarion (París 1969), la que incluye el texto introductorio de Althusser, "Avertissement aux lecteurs du Livre I du Capital" (disponible en español bajo el título "Guía para leer El Capital" [Althusser 1992]). El añadido, sin embargo, no figura en la mucho más rigurosa traducción a cargo de Jean-Pierre Lefebvre, publicada por primera vez en 1983 y que se basa directamente en la cuarta edición alemana (acaba de ser publicada una reedición enteramente revisada por el traductor [Marx 2016]). En su introducción, Lefebvre reconstruye con detalle los tropiezos y desencuentros entre Roy, Marx y Maurice La Châtre (el editor), que explican el juicio de Scaron sobre dicha primera traducción.

14 Esto, sin duda, en un sentido que podría resonar con lo que señalaba Deleuze en el último texto que publica antes de morir: "La inmanencia: Una vida..." (2011). Sin embargo, se trata de una elaboración que haría imposible siquiera la fórmula que aquí empleamos ("la inmanencia de la vida"), pues justamente "la inmanencia absoluta es ella misma y solo ella misma: no está en ninguna cosa ni pertenece a ninguna cosa... Diremos de la pura inmanencia que ella es UNA VIDA y nada más" (p. 49). De cualquier modo, la noción de inmanencia está sin duda "operando" ya en el texto de $A E$ (su publicación ocurre cuatro años después de Spinoza y el problema de la expresión, de 1968), en tanto la "univocidad" de la producción que allí se propone a propósito de la noción de "producción deseante", formaría parte de una "generalización de la ontología de la univocidad" spinoziana, que a juicio de Agamben, es lo que el último escrito de Deleuze pondría de manifiesto (Agamben 2007, p. 493). Con todo, Jameson ha llamado la atención sobre el problema que se presenta a la hora de leer esta univocidad e inmanencia en el pensamiento de Deleuze, planteando la posibilidad de leer allí no necesariamente un "monismo", sino al contrario, un "dualismo", el cual sería "la gran forma de la ideología como tal" (aunque, al mismo tiempo, Jameson tiene la prudencia de señalar que la cuestión del monismo y el dualismo en Deleuze termina siendo una cuestión "indecidible") (1997, p. 411). 


\section{La cuestión del ateísmo y el materialismo (Marx y Nietzsche)}

Varios elementos parecen converger en tal noción de "bajo materialismo" con el materialismo que estaría en juego en $A E$. Desde luego, se trata de una concepción inmanente del materialismo, toda vez que lo que se intenta eliminar es cualquier representación ideal o trascendente de la materia (o del deseo), evitar cualquier "ascenso" del pensamiento -cualquier lógica representacional-, más allá de los flujos de materia. Este rasgo sitúa tanto a la posición de Bataille como a la de D-G en un diálogo crítico con la tradición de cierto marxismo que, a partir de Engels, piensa el materialismo como "materialismo dialéctico", pero también con el propio Marx, pues se trata igualmente de un cuestionamiento o una confrontación con ciertas premisas del "materialismo histórico", particularmente -como ya se señaló- con aquella distinción entre base económica y superestructura ideológica que la noción de producción deseante viene a problematizar (sino a borrar por completo).

Tal concepción resulta inseparable de otro de los motivos que ambos materialismos comparten, y que en el caso de Bataille resulta particularmente acentuado: la cuestión del ateísmo o de la ateología. Para Bataille, el materialismo no puede ser sino ateo, y ello queda perfectamente expresado en la decapitación del acéfalo: la cabeza opera como el órgano que inevitablemente tiende a idealizar la materia, y por lo mismo, el bajo materialismo afirma la inmundicia de los pies en el barro, y vincula al obrero comunista con las partes bajas que causan repulsión a una burguesía que solo ve lo alto de los cielos. Por su parte, para D-G, el inconsciente del esquizoanálisis es tan ateo como huérfano: solo ese ateísmo y esa orfandad pueden liberar a la producción deseante de las exigencias de la representación a las que lo somete el idealismo edípico. Orfandad y ateísmo resultan ser también los dos motivos de la acefalía, y es que, de nuevo, en ambos casos es fundamentalmente a Nietzsche a quien deben tal pensamiento: no solo en cuanto ha declarado la muerte de Dios, ello es claro, sino en cuanto él mismo se declaraba "sin tierra", motivo por el cual debió crear el concepto de "Kinderland", por oposición al de "Vaterland" ("patria"): "Desterrado estoy del país de mis padres (Vaterland) y de mis madres (Mutterland). Por ello amo yo ya tan solo el país de mis hijos (Kinderland), el no descubierto, en el mar remoto: que lo busquen incesantemente ordeno yo a mis velas" (Nietzsche 2007, p. 185) ${ }^{15}$. De este modo, tanto el esquizo como el acéfalo serían, por así decirlo, igualmente nómadas e igualmente huérfanos: sin patria y sin padre ${ }^{16}$.

15 Como aclara Andrés Sánchez Pascual, el concepto de Kinderland resulta intraducible al español si se quiere mantener el juego de palabras con el de Vaterland ("patria") y el de Mutterland ("matria"), por ello es que decide traducirlo como el "país de mis hijos" (y que podría ser igualmente el "país de los niños"). Aun sin el juego de palabras, la traducción no traiciona el sentido que Nietzsche quiere dar a este concepto (Nietzsche 2007, nota 212 en p. 463).

16 "Remar juntos -comenta Deleuze- es compartir... más allá de toda ley, de todo contrato, de toda institución. Una deriva, un movimiento a la deriva o una «desterritorialización»”. 
Pero acéfalo, el principio "sin cabeza" de Bataille implica también cierto sacrificio de la razón, o al menos, del sentido. Así como Derrida ha señalado que la ateología de Bataille es a la vez una a-teleología (1967, p. 398), las palabras con que Foucault se refería al pensamiento deleuzeano resultan extensivas al pensamiento batailleano: "Para liberar la diferencia, es preciso inventar un pensamiento acategórico" (1995, p. 34). Cuando Bataille sostiene que "es necesario plantear los límites de las tendencias inherentes a la ciencia y construir un conocimiento de la diferencia no explicable, que supone el acceso inmediato de la inteligencia a una materia previa a la reducción intelectual" (2003, p. 145), lo que sugiere, a nuestro juicio, es justamente una aproximación "acategorial" a la materia, o bien, aquello que permitiría liberar esa "diferencia no explicable". En el último apartado de $N G$, Bataille planteaba esto de otro modo: "la materia... no puede definirse sino por la diferencia no lógica que representa con respecto a la economía del universo" (p. 133). Esta tentativa por pensar la materia como "diferencia no lógica", que no es sino una diferencia no dialéctica, adquiere toda su resonancia en la lógica diferencial de los flujos descrita por D-G en $A E$.

Pero finalmente, y lo que resulta de mayor interés, también en ambas propuestas se formula una versión del materialismo que concibe la identidad entre naturaleza y producción, poniendo de relieve el modo en que tanto Bataille (de manera implícita ${ }^{17}$ como D-G en $A E$ (explícitamente), recogen la noción de "ser genérico" (Gattungswesen) del joven Marx. De hecho, para D-G sería justamente tal noción la que posibilita el ateísmo, pues,

el que sabe que el lugar del hombre está en... la coextensividad del hombre y la naturaleza, ni siquiera deja subsistir la posibilidad de una cuestión "sobre un ser extraño, un ser colocado por encima de la naturaleza y el hombre": ya no necesita de esta mediación... [la negación de la existencia de Dios], pues ha alcanzado las regiones de una autoproducción del inconsciente, donde el inconsciente es tan ateo como huérfano, inmediatamente huérfano, inmediatamente ateo (Deleuze y Guattari 2009, p. 64).

D-G se inspiran aquí no solo en el texto de François Châtelet que vienen de citar, en el cual este afirmaba que si puede haber algo así como una "cuestión del ateísmo" en Marx, es simplemente la cuestión de que para Marx el ateísmo no es siquiera una "cuestión" (Châtelet 1966, p. 373), sino que D-G también tienen presente aquí el texto de Granel que había sido citado al comienzo de $A E$. Aunque no es éste el lugar para detenerse en la profundidad de dicho ensayo, Granel establece lúcidamente el vínculo entre la cuestión del ateísmo de Marx y la tesis fundamental que D-G hacen propia al inicio

Y más abajo: "El nómada, con su máquina de guerra, se opone al déspota con su máquina administrativa" (2002, p. 355 y 361$)$.

17 Aunque se trate de una lectura más bien estrecha y motivada por la corroboración de sus propias tesis (y por ello, problemática), ha sido Habermas quien explícitamente ha señalado la afinidad de Bataille con el pensamiento del "joven Marx" de los Manuscritos de 1844 (Habermas 1989, pp. 260-275). 
del $A E$ cuando sostienen que "todo es producción" (que subyace, sin duda, a la noción de "producción deseante") y que del mismo modo "ya no existe la distinción hombrenaturaleza" (Deleuze y Guattari 2009, pp. 13-14), tesis que, de acuerdo al análisis de Granel, se deriva de la afirmación de Marx en los Manuscritos de 1844: "El hombre es inmediatamente ser de la naturaleza" (Marx 2003, p. 192). Granel apunta que para comprender en su real implicancia dicha afirmación, se debe poner atención a la palabra que Marx no subraya, esto es, en "inmediatamente": "Si el hombre 'es inmediatamente el ser de la naturaleza'... es que no hay ser por fuera de 'ser de la naturaleza', y éste no es tampoco un término que subsista por sí mismo de cara al ser del hombre. Sino que uno y otro no son más que en la in-mediatez, es decir en el carácter original de su ser-el uno-el otro (o incluso, simplemente: ser-lo uno-lo otro)" (Granel 2014, p. 25). La radical identidad - 0 mejor, desdiferenciación (pues para D-G no se podría tratar de una "identidad" simple)- entre hombre y naturaleza, es precisamente lo que "quita el piso" a toda posible representación de un ser extraño o externo a esa inmediatez. De allí que, para Granel, "el ateísmo de Marx no consiste en combatir a Dios, sino en hacerlo aparecer como una 'cosa secundaria', que entonces ya no tiene sentido combatir porque por decir así se ha volatilizado, se le han retirado todo sentido y terreno" (2014, p. 29). Tal "volatilización" solo puede ocurrir cuando se asume en toda su radicalidad la fórmula marxiana de los Manuscritos.

Lo que el ensayo de Granel pone claramente de manifiesto es que materialismo ( $\mathrm{u}$ "ontología materialista", como se puede extraer de su título) y ateísmo son concomitantes, es decir, su concepción y su articulación resultan indisociables. Para arribar a tal concepción bastaría con leer a Marx, según lo que nos propone la lectura de Granel. Pero dado que se trata de la cuestión del ateísmo, es claro que allí también se abre el espacio para una combinación o para el encuentro con el pensamiento "nómada" de Nietzsche. Y es precisamente tal encuentro el que, tanto en Bataille como en D-G acontece ${ }^{18}$, dando lugar a un materialismo ateo que no sería sino un ateísmo materialista (por no conservar la denominación de materialismo histórico), y que abre la pregunta por la posibilidad de la configuración de una "ontología materialista" que en el caso de $A E$, obligaría a una lectura conjunta con Mil mesetas, obra en la que, sin embargo, tanto el nombre de Bataille como la noción de "producción deseante" desaparecen".

\section{Conclusiones}

Con la "noción de gasto", Bataille se propuso demostrar el carácter relativo (no absoluto) del principio de utilidad que domina los procesos de producción y acumulación

18 Aunque, como ya lo señalamos (ver nota 2), en el caso de D-G se trataría más precisamente del triple encuentro entre Marx, Nietzsche y Freud.

19 Lo que, en rigor, es inexacto, pues Bataille sí es mencionado una vez -anecdóticamente, es cierto- (Deleuze y Guattari 1980, p. 476), y la noción de "producción deseante" más bien es desplazada por las nociones de "máquina de guerra" y "líneas de fuga". 
capitalistas. Su ensayo pretende hacer notar el límite de lo útil ${ }^{20}$ (su sentido "restringido"), oponiendo a tales operaciones el valor y el sentido del "gasto improductivo". Los fenómenos de consumo inútil de riquezas y de dilapidación de energía que Bataille considera luego en $P M$ con mayor profundidad constituyen uno de los principales soportes teóricos (aunque también históricos y materiales) de la tesis que atraviesa gran parte de $A E$ ("todo es producción", o bien, la mentada identidad del hombre y la naturaleza), y que la categoría de "producción deseante" moviliza a lo largo del primer volumen de Capitalismo y esquizofrenia. En términos más generales, la propuesta de Bataille concibe el consumo o dilapidación improductiva y desinteresada de energía y de riquezas como un aspecto determinante en la actividad y la existencia humanas; es más, concibe el gasto improductivo como un fenómeno in- o super humano,en el sentido de que, a partir de la hipótesis de un movimiento inmanente de energía que atraviesa a la "materia viva en general" -movimiento que a su vez condiciona los procesos históricos y sociales-, se trata de acontecimientos que superan o atraviesan la agencia o la voluntad humanas en cuanto tales ${ }^{21}$.

Lo que la primera parte de este artículo se propuso demostrar, es en cierto modo la desproporción, por así decirlo, que puede aparecer entre, por un lado, el lugar relativamente menor que cabría atribuir a Bataille dentro de $A E$, dado su escasa (si no única) mención a lo largo de dicha obra y el lugar marginal en el que figura (una nota al pie), y lo que, por otro lado, luego de una lectura más detallada, permite visualizar como la real importancia que tienen los trabajos de Bataille en la elaboración teórica de $A E$, la cual, como decíamos en la introducción, supera con creces la de ser "una más" de las múltiples referencias bibliográficas que la alimentan.

Un segundo aspecto que nos ha interesado poner de relieve es la manera en que tanto Bataille como D-G ensayan una original y productiva combinación entre el pensamiento de Marx y el de Nietzsche, que sin ser completamente explícito en ambos casos (ni tampoco la única combinación en juego en los trabajos de cada cual), representa una empresa teórica que, junto a trabajos de otros autores franceses como Lyotard, Debord, Sollers o incluso el último Althusser, siguen exigiendo hoy una interrogación profunda, así como una igualmente imperativa búsqueda de nuevas posibilidades, no la limite de l'utile (1976; trad. esp.: 2005).

$21 \quad$ Es famosa (y, sin duda, polémica) la explicación que a partir de tal hipótesis Bataille ofrece respecto de las dos guerras mundiales, así como de los conflictos sociales y las grandes revoluciones de la historia: "Estos excesos de fuerza viva... son, de hecho, los factores de ruina más peligrosos... la existencia del excedente (en ciertos puntos) ha llevado siempre a numerosos seres humanos y grandes cantidades de bienes útiles a la destrucción de las guerras" (Bataille 1987, p. 60). Al respecto, Jean Piel observaba que: "Todo el problema consiste en saber cómo, en el seno de esta economía general, se utiliza el excedente. El uso dado al excedente es 'la causa de los cambios de estructura', es decir, de toda la historia de la civilización... [de modo que] el futuro depende de la elección que los hombres de hoy hagan del modo de gastar el inevitable excedente" (1987, p. 19). 
solo para el marxismo, sino para el pensamiento político en general. Esto por cuanto, como se ha podido ver, tanto la noción de gasto improductivo de Bataille como la de producción deseante de D-G desplazan de manera radical la perspectiva "humanista" o "subjetivista" que por tanto tiempo (y con tanta profundidad) ha permanecido en distintas interpretaciones de la obra de Marx, aunque de manera más general, en diferentes variantes de una filosofía política que no logra desembarazarse de la llamada "metafísica del sujeto". Como bien lo expresa Sibertin-Blanc, haciendo propia una fórmula althusseriana, la identidad (y, por tanto, reversibilidad) entre "hombre" y "naturaleza" que supone la noción de producción deseante, significa que "el deseo se realiza en su totalidad en un proceso sin sujeto" 22 (2010, p. 21), y que en ese sentido excluye todo presupuesto externo a su propio despliegue ${ }^{23}$ (sea este el de la naturaleza con respecto al hombre, el de Dios respecto al mundo, el del objeto en relación con el sujeto, o el del inconsciente edípico en relación con el inconsciente como máquina, etc.). De cualquier modo, nos parece que tanto en el caso de Bataille como en el de D-G, se trata de pensar estos problemas a partir de "la flexibilidad y la potencia del marxismo", como lo expresara Bataille en un breve artículo de 1932 escrito junto a Raymond Queneau para la revista La critique sociale (Bataille 2003, p. 109).

Por último, aunque en este punto no podemos más que instalar el problema en toda su apertura y complejidad, esta confrontación con el marxismo, y particularmente con el andamiaje conceptual del materialismo histórico, sugiere la posibilidad también de pensar tanto desde Bataille como desde D-G (aunque sobre todo con la lectura y la inscripción que en $A E$ hacen los últimos con el primero), una cierta "ontología materialista", no solo en el sentido en el que Granel leía los Manuscritos de 1844 de Marx, sino también a partir de una híbrida "corriente subeterránea" de dicha ontología, que incluiría a lo menos a Spinoza, Bergson y Simondon (pero que, según la indicación de Althusser, a quien no por nada aquí parafraseamos, se reomontaría incluso al atomismo presocrático ${ }^{24}$ ). Por lo demás, es en este sentido que los propios trabajos de Deleuze (sobre Bergson, Nietzsche o Spinoza), y quizás especialmente sus trabajos junto a

22 Proceso "sin origen, sin fin, sin sujeto" (Sibertin-Blanc 2010, p. 33). La célebre fórmula althusseriana quedó expresada en su "Respuesta a John Lewis": "Es preciso decir, en efecto, que la 'historia' de producción de conocimientos es, como toda la historia, también un proceso sin sujeto, y que los conocimientos científicos surgen... como resultado histórico de un proceso dialéctico, sin Sujeto ni Fin(es)" (1974, p. 42).

23 En otro lugar, Sibertin-Blanc señala: "El deseo no es un estado de un sujeto, ni una tensión hacia una cosa en la objetividad, o hacia su representación en el sujeto. Es una actividad transindividual de elaboración" (2010, p. 24). La noción de "transindividual" proviene del trabajo de Simondon sobre la individuación y lo pre-individual (2009), trabajo que Étienne Balibar ha incorporado a su propia reflexión, y que es de donde Sibertin-Blanc la recoge (Balibar 2010, pp. 30-32; 2009).

24 'De Epicuro a Marx siempre ha subsistido, aunque encubierto... el ‘descubrimiento' de una tradición profunda que buscaba su base materialista en una filosofía del encuentro (y así, pues, más o menos atomista, ya que el átomo es la figura más simple de la individualidad en su 'caída') después de haber rechazado radicalmente toda filosofía de la esencia (Ousia, 
Guattari, han podido ser leídos. Sibertin-Blanc, por ejemplo, caracteriza el trabajo conjunto de D-G como un "pensamiento de la potencia" ("spinozista, si se quiere", añade enseguida) que tendría como uno de sus efectos principales la conformación de una "ontología de la afirmación", que consistiría ante todo en una refutación de todo tipo de análisis de las formas sociales en términos de "deficiencia", "falta" o "privación", postulando, por el contrario, la tesis de que "toda realidad se determina como posición de potencia, afirmación de una perfección ('cantidad de realidad') bajo una potencia determinada" (Sibertin-Blanc 2013, p. 41) 25. Mengue, a su vez, habla en reiteradas ocasiones de una "ontología deleuzeana" o de una "ontología de lo social" en Deleuze (2008) ${ }^{26}$. También Paul Patton, que ha dedicado buena parte de su trabajo a pensar y reconstruir una "política" en Deleuze, sostiene que D-G proveen de hecho un nuevo lenguaje con el cual describir los "movimientos micropolíticos" y los "procesos infrapolíticos" que en definitiva pondría en evidencia la configuración de una "ontología social de ensamblajes y procesos" (2011, p. 117) ${ }^{27}$. Holland, por su parte, prefiere hablar directamente de una "ontología materialista de la repetición" o de una "ontología materialista de la diferencia", a partir de la articulación que puede establecerse entre Diferencia y repetición y $A E(1999, \text { p. } 25 \text { y } 27)^{28}$. En la mayor parte de los casos, como se ve, existe la intuición -o incluso la convicción- de que en la obra de Deleuze, y particularmente en sus trabajos en colaboración con Guattari, es posible identificar, pensar y elaborar una ontología, la que tal vez precisamente por su diferentes modulaciones (política o social, de la repetición o de la diferencia, materialista o de la afirmación), reclama ser tomada como un problema por sí mismo.

$$
* * *
$$

En ¿Qué es la filosofía? D-G señalaban que "si se puede seguir siendo platónico, cartesiano, kantiano hoy en día [y habría que agregar aquí también "marxiano"], es

Essentia, Wessen), de la Razón (Logos, Ratio, Vernunft), y, por tanto, del Origen y del Fin..." (Althusser 2002, p. 54).

25 Aunque es cierto que, más adelante, recordando la citada frase de D-G en Mil mesetas, que afirma que "antes que el ser, está la política" (Deleuze y Guattari 1980, p. 249), SibertinBlanc añade a continuación que "antes de la ontología, [está] la estrategia" (2013, p. 226). Esto se explicaría, por lo demás, atendiendo al subtítulo de este libro: "Ensayo sobre el materialismo histórico-maquínico" (y no "ensayo sobre el materialismo ontológico", por ejemplo).

26 Y en su comentario a Diferencia y repetición, habla incluso de una "ontología de la univocidad" (Mengue 2008, p. 231).

27 También habla de una "ontología política" de la cual se puede derivar una cierta normatividad (Patton 2011, p. 117). Patton desarrolla extensamente esta lectura de Deleuze en Patton (2010) y (2000).

28 Buchannan, en un sentido similar, habla de una "ontología de máquinas sociales" (2008, pp. 90-96). 
porque estamos legitimados para pensar que sus conceptos pueden ser reactivados en nuestros problemas e inspirar [unos] conceptos nuevos que hay que crear" (2009b, p. 33). Así, no habría que repetir lo que los grandes filósofos dijeron, no habría que "cuidar el parecido", sino más bien volver a hacer hoy lo que ellos hicieron en su tiempo. Me parece que tal trabajo, el de crear conceptos para unos problemas que necesariamente cambian, es precisamente lo que se halla en juego en el materialismo que tanto Bataille como D-G han intentado elaborar en los trabajos aquí comentados.

\section{Agradecimientos}

El origen de este trabajo fue una ponencia presentada en el simposio "Deleuze en diálogo", organizado por Gonzalo Montenegro, en el marco del IV Congreso Iberoamericano de Filosofía, realizado en noviembre de 2012 en la ciudad de Santiago de Chile. Agradezco a Gonzalo por la invitación a dicha instancia así como por sus comentarios y observaciones realizadas en tal ocasión.

\section{Referencias bibliográficas}

Agamben, Giorgio (2007), "La inmanencia absoluta", La potencia del pensamiento. Buenos Aires: Adriana Hidalgo, pp. 481-522.

Althusser, Louis (1974), Para una crítica de la práctica teórica. Respuesta a John Lewis. Madrid: Siglo XXI. (2002), Para un materialismo aleatorio. Madrid: Arena.

Balibar, Étienne (2009), Spinoza. De la individualidad a la transindividualidad. Córdoba: Encuentro.

(2010), La philosophie de Marx. París: La Découverte.

Bataille, Georges (2005), El límite de lo útil. Madrid: Losada.

(1997), El ojo pineal, precedido de El ano solar y Sacrificios. Valencia: Pre-Textos.

(2003), La conjuración sagrada. Ensayos 1929-1939. Buenos Aires: Adriana Hidalgo.

(2007), La parte maldita. Buenos Aires: Las Cuarenta.

(1987), La parte maldita precedida de La noción de gasto. Barcelona: Icaria.

(1996), Lo que entiendo por soberanía. Barcelona: Paidós.

(1970), Euvres complètes I. París: Gallimard.

(1970), Euvres complètes II. París: Gallimard.

(1976), "La limite de l'utile”, en Euvres complètes VIII. París: Gallimard, pp. 181-280.

(1974), Obras escogidas. Barcelona: Barral. 
Buchannan, Ian (2008), Deleuze and Guattari's Anti-Oedipus. A Reader's Guide. Londres y Nueva York: Continuum.

Châtelet, François (1966), "La question de l'athéisme de Marx”, Études philosophiques 21(3): 371-384.

Deleuze, Gilles (1996), Conversaciones. Valencia: Pre-Textos, 1996. (2011), "La inmanencia, una vida", Inmanencia 1: 49-51. (1983), Nietzsche et la philosophie. París: PUF. (1986). Nietzsche y la filosofía. Barcelona: Anagrama. (2002), "Penséenomade", L'îledéserte. Textes et entretiens 1953-1974. París: Les Editions de Minuit, pp. 351-364.

Deleuze, Gilles y Guattari, Félix (2009), El Anti-Edipo. Buenos Aires: Paidós. (1972/1973), L'Anti-CEedipe. París: Les Editions de Minuit. (1980), Mille plateaux. París: Les Editions de Minuit. (2009), ¿Qué es la filosofía? Barcelona: Anagrama.

Derrida, Jacques (1967), L'écriture et la différence. París: Éditions du Seuil.

Foucault, Michel (1995), “Theatrum Philosophicum”, en Foucault, Michel y Deleuze, Gilles. Theatrum Philosophicum seguido de Repetición y diferencia. Barcelona: Anagrama.

Granel, Gérard (2014), "La ontología marxista de 1844 y la cuestión del 'corte"”, Actuel Marx/Intervenciones 16: 15-68.

Grindon, Gavin (2010), "Alchemist of theRevolution. TheAffectiveMaterialism of Georges Bataille", Third Text 24-3: 305-317.

Habermas, Jürgen (1989), El discurso filosófico de la modernidad. Madrid: Taurus.

Holland, Eugene W. (1999), Deleuze and Guattari's Anti-Oedipus. Introduction to schisoanalysis. Londres y Nueva York: Routledge.

Jameson, Fredric (1997), "Marxism and Dualism in Deleuze", The South Atlantic Quarterly 96-3: 393-416.

Macherey, Pierre (2003), "Georges Bataille y la inversión materialista”, ¿En qué piensa la literatura? Bogotá: Siglo del Hombre, pp. 141-164.

Marx, Karl (2005), El capital, Tomo I, Vol. 3, El Proceso de producción del Capital. México: Siglo XXI.

(1989), Contribución a la crítica de la economía política. Moscú: Progreso.

(2003), Manuscritos de economía y filosofía. Madrid: Alianza. (2009), Manuscritos de economía y filosofía. Madrid: Alianza.

Mengue, Philippe (2008), "El Anti-Edipo. Capitalistmo y Esquizofrenia”, Deleuze o el sistema de lo múltiple. Buenos Aires: Las Cuarenta, pp. 269-298.

Montenegro, Vicente (2015), "El materialismo de Georges Bataille. Una lectura desde Nietzsche y Marx", Ideas y Valores 64 (159): 195-226.

Nietzsche, Friedrich (2007), Así habló Zaratustra. Madrid: Alianza. 
Patton, Paul (2000), Deleuze and the Political. Londres y Nueva York: Routledge.

(2010), Deleuzian Concepts: Philosophy, Colonization, Politics. Stanford: Stanford University Press.

(2011), "What is Deleuzean Political Philosophy", Crítica Contemporánea. Revista de Teoría Política 1: 115-126.

Piel, Jean (1987), “Introducción”, en Georges Bataille, La parte maldita. Barcelona: Icaria, pp. 11-21.

Sartre, Jean-Paul (1960), “Un nuevo místico”, El hombre y las cosas. Buenos Aires: Losada, pp. 111-145.

Sibertin-Blanc, Guillaume (2010), Deleuze y el Antiedipo. La producción del deseo. Buenos Aires: Nueva Visión.

(2013), Politique et État chez Deleuze et Guattari. Essai sur le matérialisme historico-machinique. París: PUF.

Simondon, Gilbert (2009), La individuación a la luz de las nociones de forma y de información. Buenos Aires: Cactus.

Sollers, Philippe (1977), "El techo", La escritura y la experiencia de los límites. Valencia: Pre-Textos, 1977.

Wendling, Amy E. (2007), "Sovereign Consumption as a Species of Communist Theory: Reconceptualizing Energy", en S. Winnubst, ed., Reading Bataille Now. Indiana: Indiana University Press, pp. 35-53.

Zourabichvili, François (2003), Le voucabulaire de Deleuze. París: Ellipses. 